\title{
Frequent urination causing sleepless nights in a 64-year-old man
}

\author{
Jonathan D. Gill MBChB, C. Shekhar Biyani MBBS MS
}

Competing interests: C. Shekhar Biyani has received education grants to attend conferences and payment for courses or lectures from

GlaxoSmithKline, Ethicon, Astella, Storz and Olympus. No other competing interests were declared.

This article has been peer reviewed.

Correspondence to: C. Shekhar Biyani, shekhar.biyani@midyorks .nhs.uk

CMAJ 2015. DOI:10.1503 /cmaj.131771
A 64-year-old man presents to his primary care physician with a six-month history of frequent urination during the night. The patient reports having no such symptoms during the day. His general health is good, aside from hypertension treated with a diuretic. He drinks five to six cups of coffee daily.

\section{What is the cause of this patient's symptoms?}

This patient has nocturia, which is defined by the International Continence Society as waking at least once during the night to void, with each void being preceded and followed by sleep. ${ }^{1}$ Patients can be monosymptomatic (i.e., having symptoms only at night) or have concomitant daytime symptoms (e.g., frequency and reduced flow).

Before diagnosing nocturia, it is important to consider other causes for waking such as noise, pain, depression or disturbance by a partner; if woken for such reasons, many people will empty their bladder before returning to sleep.

The three most common types of nocturia are nocturnal polyuria (normal total daily urine output, and $>33 \%$ of the total daily urine output occurring at night in patients aged $>65 \mathrm{yr}$ or $>20 \%$ of total output in patients aged $<65 \mathrm{yr}$ ), global polyuria (24-h urine output $>3200 \mathrm{~mL}$ ) and bladder dysfunction..$^{2-6}$

A focused history can help clarify the type and cause of nocturia (Box 1). ${ }^{3-6}$ Because this patient has symptoms only at night, evening consumption of fluids including alcohol and caffeinated beverages and the use of specific medications associated with nocturia, such as diuretics, should be assessed. ${ }^{2-4}$ Breathing problems and snoring during sleep will suggest the need for sleep studies. ${ }^{5,7}$ Conditions that may cause fluid retention and dependent peripheral edema should be considered, because a redistribution of the accumulated fluid to the intravascular compartment while the patient is recumbent may cause nocturia. ${ }^{2,3}$
For patients with concomitant daytime symptoms, it is important to ask about bladder storage symptoms that would suggest the presence of an overactive bladder. Symptoms of hesitancy, poor stream and incomplete bladder emptying suggest the possibility of bladder outlet obstruction. ${ }^{4,5}$ Nocturnal enuresis in an older man should prompt consideration of chronic retention with overflow incontinence. ${ }^{4}$ In the presence of daytime urinary frequency, it is important to exclude diabetes mellitus and diabetes insipidus. ${ }^{2-4}$

\section{What should be assessed in a physical examination?}

A physical examination should assess for neurologic conditions (e.g., neck or back pain, limb weakness or sensory loss), lower limb edema and signs of heart failure. An abdominal examination should be included to assess for a palpable bladder, and a rectal examination should be done to assess anal tone, as well as prostate size and consistency. ${ }^{2-4}$

\section{What investigations should be ordered?}

The patient should be asked to complete a frequency volume chart for a minimum of three full days. This diary of the volume and type of fluids ingested, as well as the volume and time of each void and incontinence episode, is essential to assess for the presence of nocturnal polyuria. ${ }^{2-6}$

Urine dipstick testing can exclude urinary tract infection, hematuria, glycosuria and diabetes insipidus (specific gravity $<1.005$ ).$^{2-7}$ Laboratory investigations for causes of nocturia may include blood tests for glucose, urea and electrolyte levels. ${ }^{4,5}$ The presence of nocturia does not confer an increased risk of prostate cancer, and patients should be made fully aware of the implications of testing for prostate-specific antigen. ${ }^{4}$

For patients with concomitant daytime symptoms, post-void residual urine should be measured on ultrasonography to confirm a bladder outlet obstruction..$^{2-4}$ A questionnaire, such as the Epworth Sleepiness Scale, ${ }^{8}$ can be used to help 
diagnose a sleep disorder. For example, a score of more than 10 on the Epworth scale merits referral for a sleep study. ${ }^{8}$

\section{What management options should be offered?}

Lifestyle changes such as restricting fluid intake in the evening, engaging in moderate exercise in the evening and reducing caffeine and alcohol intake may be helpful but have not been assessed in randomized controlled trials (RCTs). ${ }^{2-6}$

In the presence of presacral edema or swelling of the lower limbs, limited evidence supports elevation of the legs in the evening and the use of compression stockings. ${ }^{2,3}$ Guidelines suggest that, based on the results of three RCTs, taking a diuretic in the afternoon should be considered. ${ }^{2,3}$ To minimize the risk of falls, the use of sedatives to treat disturbed sleep secondary to nocturia should be avoided. ${ }^{5}$

When conservative measures have failed and the nocturia is related to nocturnal polyuria, guidelines supported by evidence from several RCTs have suggested the efficacy of desmopressin taken orally. ${ }^{4}$ However, because of the risk of hyponatremia (particularly in older patients), sodium levels should be measured before and within a few days of the first dose. ${ }^{4,9}$

In patients with reduced bladder capacity or overactive bladder, bladder retraining with or without anticholinergic medications has been shown to be effective in several guidelines supported by multiple RCTs. ${ }^{3-6}$ Other treatment options for specific causes of nocturia are outlined in Box 1.

Referral should be considered in the presence of hematuria, suspected malignant growth of the bladder or prostate, large post-void residual urine, treatment failure and sleep disorders. ${ }^{4-6}$

\section{What follow-up should be arranged?}

A follow-up appointment in six weeks will provide an opportunity to review the patient's frequency volume chart and to discuss further management if the initial treatment plan fails.

\section{Case revisited}

The patient was counselled to reduce his caffeine and fluid intake in the evening and to take his daily diuretic medication before noon. In addition, he was given a frequency volume chart to complete. At the six-week follow-up appointment, the patient reported that his symptoms had resolved with the recommended course of action.

\section{Box 1: Causes and management of nocturia ${ }^{3-6}$}

Causes

Management

Nocturnal polyuria (nocturnal urine volume $>33 \%$ of $24-\mathrm{h}$ urine volume in patient aged $>65 \mathrm{yr}$; nocturnal urine volume $>20 \%$ of 24 -h urine volume in patient aged $<65 \mathrm{yr}$ )

- Late evening fluid/coffee intake

- Heart failure

- Idiopathic

- Hypoproteinemia

- Sleep apnea syndrome

Global polyuria (24-h urine output $>3200 \mathrm{~mL}$ )

- Diabetes mellitus

- Polydipsia (psychogenic)

- Nephrogenic diabetes insipidus (e.g., secondary to lithium use)
- General lifestyle advice

- Diuretic agent to be taken in the mid or late afternoon

- Desmopressin

\section{Bladder storage or voiding dysfunction}

- Bladder outlet obstruction with high residual urine

- Detrusor overactivity

- Cystitis

- Sensory urgency

- Malignant growth of the bladder or prostate

- $\alpha$-blocker, 5 - $\alpha$-reductase inhibitor

- Anticholinergic agent + bladder retraining

- Antibiotic

- Bladder retraining

- Referral to hospital

- Satisfactory sugar control

- Review medications and fluid consumption

\section{References}

1. van Kerrebroeck P, Abrams P, Chaikin D, et al. The standardisation of terminology in nocturia: report from the Standardisation Sub-committee of the International Continence Society. Neurourol Urodyn 2002;21:179-83.

2. Weiss JP, Bosch JL, Drake M, et al. Nocturia Think Tank: focus on nocturnal polyuria: ICI-RS 2011. Neurourol Urodyn 2012; 31:330-9.

3. Clinical guidelines for nocturia. Int J Urol 2010;17:397-409.

4. European Association of Urology guidelines: 2014 edition. Arnhem (the Netherlands): European Association of Urology; 2014. Available: www.uroweb.org/guidelines. (accessed 2014 June 24).

5. Nocturia guideline: a guideline for assessing and treating patients with nocturia, in a primary care setting in New Zealand. Drury (NZ): New Zealand Continence Association; 2005. Available: www.continence.org.nz/pdf/nocturia_guidelines.pdf (accessed 2014 July 3).

6. Weiss JP, Blaivas JG, Blanker MH, et al. The New England Research Institutes, Inc. (NERI) Nocturia Advisory Conference 2012: focus on outcomes of therapy. BJU Int 2013;111:700-16.

7. Loh JA, Verbalis JG. Disorders of water and salt metabolism associated with pituitary disease. Endocrinol Metab Clin North Am 2008;37:213-34.

8. Johns MW. A new method for measuring daytime sleepiness: the Epworth sleepiness scale. Sleep 1991;14:540-5.

9. Weatherall M. The risk of hyponatremia in older adults using desmopressin for nocturia: a systematic review and meta-analysis. Neurourol Urodyn 2004;23:302-5.

Affiliations: Department of Urology (Gill), St. James's University Hospital, Leeds, UK; Department of Urology (Biyani), Pinderfields Hospital, Wakefield, UK

Contributors: Both of the authors contributed equally to writing and revising the manuscript, and have approved the final version submitted for publication. 